\title{
Methadone and intake of palatable fluids
}

\author{
MICHAEL L. ABELSON and LARRY D. REID \\ Rensselaer Polytechnic Institute, Troy, New York
}

\begin{abstract}
Rats were maintained on a daily schedule of water deprivation for $22 \mathrm{~h}$, followed by $2 \mathrm{~h}$ of access to water and test solution. For one group, the test solution was $0.9 \% \mathrm{NaCl}$. For another group, the test solution was $24 \%$ sucrose. After rats' intakes were stable, both groups were given placebos or doses of methadone. Methadone $(0.5$ and $1.0 \mathrm{mg} / \mathrm{kg}$ ) increased intakes of both the salty and the sweet solutions. These data confirm that certain opioids increase intake of palatable ingesta and indicate that the prescription of methadone may have a side effect of unduly enhancing intake of certain foods.
\end{abstract}

This experiment stems from two sources of information. One source is the extensive data base that indicates that opioids modulate ingestion by laboratory subjects, particularly rats (see Reid, 1985, for review). The other source is conversations with directors of methadone maintenance clinics (e.g., G. Penrose, personal communication, 1986), who indicate that people taking methadone as treatment for heroin addition often rapidly gain weight and have high blood pressure. Since we knew of no studies that assess the effects of methadone on ingestion of palatable fluids using rats, and since methadone is rather widely prescribed, we decided to conduct this simple assessment of methadone's effects on intake of sweet (sucrose) and salty solutions by rats.

Naloxone, the prototypic antagonist at opioid receptors, reduces intake of a wide variety of ingesta (Reid, 1985) across species. Small doses of morphine, the agonist at the receptors, increase rats' intake of sweet solutions (saccharin or sucrose) (Calcagnetti \& Reid, 1983; Czirr \& Reid, 1986), salty solutions (Bertino et al., in press), and solutions containing ethanol (Hubbell et al., 1986; Reid \& Hunter, 1984). Since morphine and methadone are very similar drugs, and since we have already shown that small doses of methadone increase intake of a sweetened alcoholic beverage in rats (Mudar, LeCann, Czirr, Hubbell, \& Reid, 1986), we expected that small doses of methadone would increase intakes of sucrose and salt solutions. The results of this simple experiment verified our expectations.

\section{METHOD}

\section{Subjects and Apparatus}

Forty male Sprague-Dawley rats (Taconic Farms, Germantown, NY) were housed individually in a colony room with constant temperature $\left(24^{\circ} \mathrm{C}\right)$ and $12 \mathrm{~h}$ of artificial light (lights on at $0800 \mathrm{~h}$ ). They were maintained on Wayne Rodent Blox ad lib and on a schedule of deprivation of water as specified. Fluids were presented in home cages by way of ballpoint sipping tubes. Bottles were weighed to the nearest $0.1 \mathrm{~g}$ before and after presentation of fluids, and the differences were corrected for spillage (Myers, Ng, Marzuki, Myers, \& Singer, 1984).

This research was supported, in part, by a grant from the National Institute on Alcohol Abuse and Alcoholism. We thank Jean Bestle and Betty Osganian for their help with the clerical tasks. Please address correspondence to Larry D. Reid, Department of Psychology, Rensselaer Polytechnic Institute, Troy, NY 12180.

\section{Procedure}

Shortly after arrival at the laboratory, when their mean weight was about $350 \mathrm{~g}$, rats were placed on a schedule of deprivation of water $(22 \mathrm{~h})$ followed by presentation of both tap water and test solution $(2 \mathrm{~h})$. This daily regimen was maintained for 9 days prior to the experimental procedures and continued throughout them.

One group's $(n=20)$ test solution was $0.9 \% \mathrm{NaCl}$, and the other group's was $24 \%$ sucrose solution (i.e., $24 \mathrm{~g}$ of sucrose plus $76 \mathrm{~g}$ of tap water for every $100 \mathrm{~g}$ of solution). Groups were further subdivided to receive either a lower $(0.5 \mathrm{mg} / \mathrm{kg})$ or a higher $(1.0 \mathrm{mg} / \mathrm{kg})$ dose of methadone-hydrochloride. All injections were given in a volume of $1 \mathrm{ml} / \mathrm{kg}$ subcutaneously. Consequently, there were two groups for each

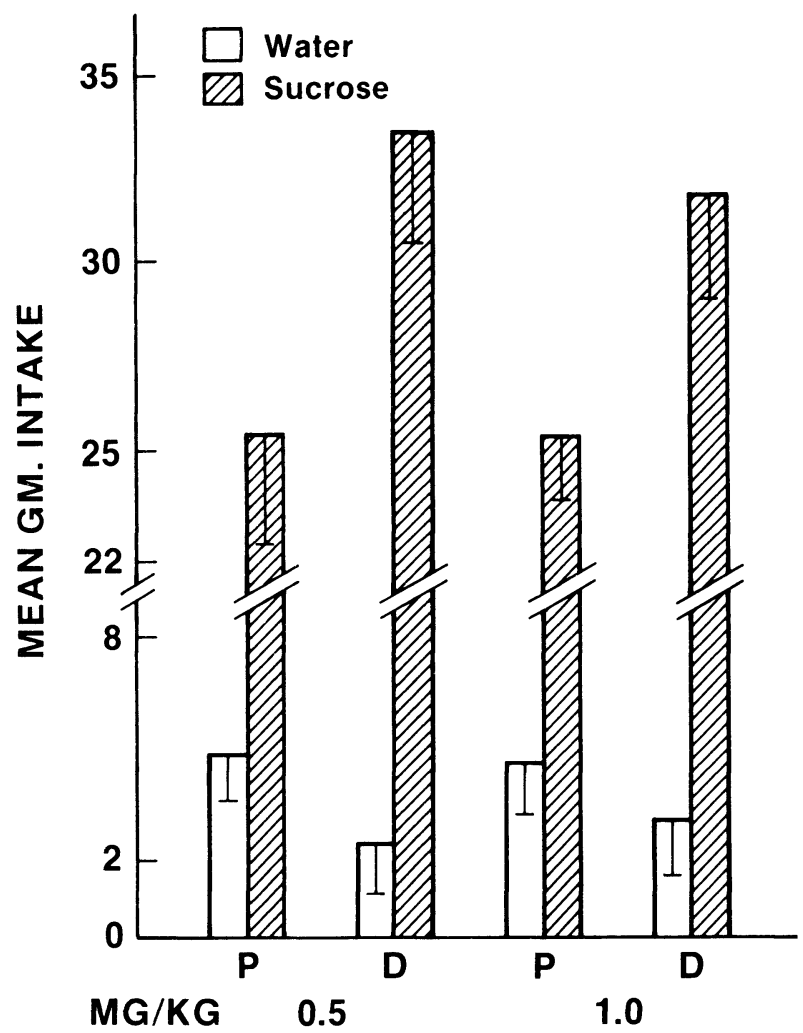

Figure 1. The mean grams of intake of water and sucrose solution taken by rats after an injection of either the placebo or one of two doses of methadone $(0.5$ or $1.0 \mathrm{mg} / \mathrm{kg})$. $P$ indicates values when placebo was given. D indicates values when drug (methadone) was given. The lines within the bars indicate the standard error of means of the scores. 
test solution and one group for each dose, or 10 rats per dose for each test solution.

After the rats experienced 9 days of the fluid-deprivation regimen, injections were given. One-half of the rats received an injection of placebo $10 \mathrm{~min}$ prior to the opportunity to take fluids. Before the next day's session, they received one of two doses of methadone. The other half received their injections beginning 1 day later, as a control for effects that might be associated with any given day. Since we could not, however, discern differences in outcomes depending on whether or not injections were started one day or the other, we ignored this factor in subsequent analyses of data. Consequently, the data associated with each test solution conform to an experimental design for a $2 \times 2 \times 2$ factorial analysis of variance (ANOVA) having repeated measures with a factor for dose of methadone $(0.5$ or $1.0 \mathrm{mg} / \mathrm{kg}$ ), condition (placebo or drug), and kind of fluid (water or test solution). Preference ratios (grams of test solution divided by grams of total fluids) were also computed.

\section{RESULTS}

Figures 1 and 2 summarize the effects of methadone on intakes. Methadone reliably increased intakes of both saline solution $[F(1,36)=5.0, p<.02]$ and sucrose solution $[F(1,36)=15.1, p<.0001]$. Water intakes were not reliably modified. Increments in preference ratios were observed across the sucrose groups $[t(19)=2.02$, $p<.05]$. Changes in preference ratios for subjects in

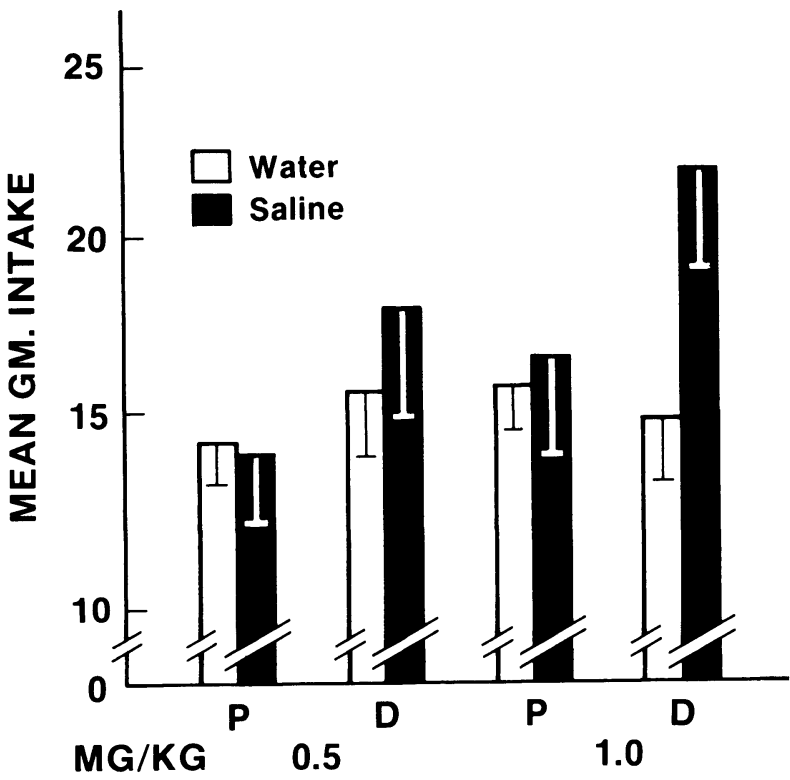

Figure 2. The mean grams of intake of water and saline solution taken by rats after an injection of either placebo or one of two doses of methadone. $P$ indicates values when placebo was given. $D$ indicates values when drug (methadone) was given. The lines within the bars indicate the standard error of means of the scores. the saline group were not statistically significant across conditions. We presume that $0.9 \% \mathrm{NaCl}$ does not completely reduce thirst drive in water-deprived rats, and this may account for substantial water intake across conditions. The condition $\times$ dose interaction for preference ratios of the sucrose group was not statistically significant. Differences in dose produced neither a main effect nor reliable two- or three-way interactions.

\section{DISCUSSION}

As mentioned in the introduction, the expectation that methadone would increase intakes of palatable solutions in this type of testing was verified. There are a number of implications that can be derived from our results. The conclusion that methadone would promote enhanced intake of sweets, salty foods, and flavored alcoholic beverages is probably not limited by the possibility of tolerance to the enhancing effect, since we have observed no such tolerance with morphine (Hubbell et al., 1986; Hubbell, Czirr, \& Reid, 1987). These data are compatible with the generalization that opioids are modulators of ingestion. The obvious implication is the possibility of a side effect of methadone maintenance treatment, which is a propensity to overconsume food and drink and suffer adverse consequences. Also, but not so obvious an implication, these data support the use of naltrexone rather than methadone as the treatment for heroin addiction, since the side effects of naltrexone are apt to be less serious than those of methadone.

\section{REFERENCES}

Bertino, M., Abelson, M. L., Marglin, S. H., Neuman, R., BurkHARDT, C. A., \& REID, L. D. (in press). Small doses of morphine increase intake of and preference for salty solutions among rats. Pharmacology Biochemistry \& Behavior.

CalcagnetTi, D. J., \& ReID, L. D. (1983). Morphine and acceptability of putative reinforcers. Pharmacology Biochemistry \& Behavior, $18,567-569$.

CzIrR, S. A., \& ReID, L. D. (1986). Demonstrating morphine's effects on sucrose-intake. Brain Research Bulletin, 17, 639-642.

Hubbell, C. L., Czirr, S. A., Hunter, G. A., Beaman, C. A., LeCANN, N. C., \& ReID, L. D. (1986). Consumption of ethanol solution is potentiated by morphine and attenuated by naloxone persistently across daily repeated administrations. Alcohol, 3, 39-54.

Hubbell, C. L., CzirR, S. A., \& ReID, L. D. (1987). Persistence and specificity of small doses of morphine on intake of alcoholic beverages. Alcohol, 4, 149-156.

Mudar, P. J., LeCann, N. C., Czirr, S. A., Hubbell, C. L., \& Reid, L. D. (1986). Methadone, pentobarbital, pimozide and ethanol-intake. Alcohol, 3, 303-308.

Myers, W. D., Ng, K. T., Marzuki, S., Myers, R. D., \& Singer, G. (1984). Alteration of alcohol drinking in the rat by peripherally selfadministered acetaldehyde. Alcohol, 1, 229-236.

REID, L. D. (1985). Endogenous opioid peptides and regulation of drinking and feeding. American Journal of Clinical Nutrition, 42, 1099-1132.

ReID, L. D., \& Hunter, G. A. (1984). Morphine and naloxone modulate intake of ethanol. Alcohol, 1, 33-37.

(Manuscript received for publication June 23, 1987). 